\title{
Persistent hyperthyroidism and de novo Graves' ophthalmopathy after total thyroidectomy
}

\author{
Wei Lin Tay1, Wann Jia Loh², Lianne Ai Ling Lee ${ }^{3}$ and Chiaw Ling Chng' \\ 1Department of Endocrinology, Singapore General Hospital, Singapore, Singapore, 2Department of Endocrinology, \\ Changi General Hospital, Singapore, Singapore, and 3Department of Pathology, Sengkang Health, \\ Singapore, Singapore
}

Correspondence should be addressed to W L Tay

Email

weilin.tay@mohh.com.sg

\section{Summary}

We report a patient with Graves' disease who remained persistently hyperthyroid after a total thyroidectomy and also developed de novo Graves' ophthalmopathy 5 months after surgery. She was subsequently found to have a mature cystic teratoma containing struma ovarii after undergoing a total hysterectomy and salpingo-oophorectomy for an incidental ovarian lesion.

\section{Learning points:}

- It is important to investigate for other causes of primary hyperthyroidism when thyrotoxicosis persists after total thyroidectomy.

- TSH receptor antibody may persist after total thyroidectomy and may potentially contribute to the development of de novo Graves' ophthalmopathy.

\section{Background}

The coexistence of Graves' disease and struma ovarii is uncommon, resulting in delayed diagnosis. While de novo Graves' ophthalmopathy has been seen after definitive treatment of Graves' disease with radioactive iodine, it is uncommon after total thyroidectomy. Our patient had persistent thyrotoxicosis as well as the development of de novo Graves' ophthalmopathy after total thyroidectomy, both mediated by the presence of functioning struma ovarii in a mature cystic teratoma.

\section{Case presentation}

Our patient is a 52-year-old Chinese female with a history of myasthenia gravis diagnosed in 2012 for which she underwent thymectomy in February 2013 for a stage 1 thymoma. She was previously diagnosed with a multinodular goiter in 2009. Both her brother and sister have hypothyroidism.

She presented in May 2013 with worsening fatigability as well as generalized weakness, which was diagnosed as a myasthenic flare. Further history revealed weight loss, palpitations, heat intolerance and reduced menstrual flow. On examination, she had a fine tremor in her outstretched hands and a nodular goiter, which was larger on the right than the left. She had no features of Graves' ophthalmopathy (GO). Her thyroid hormone levels are documented in Table 1 . TSH receptor antibody (TRAb) was elevated at 
Table 1 Trend of thyroid hormone and antibody levels with corresponding events.

\begin{tabular}{|c|c|c|c|c|c|c|c|}
\hline & Reference interval & May 2013 & Feb 2015 & Jun 2015 & Mar 2016 & Apr 2016 & Jun 2016 \\
\hline fT3 pmol/L & $3.2-5.3$ & 6.8 & & 42.9 & 5.7 & & \\
\hline fT4 pmol/L & $8.8-14.4$ & 39.2 & 12.3 & $>77.2$ & 9.0 & 26.1 & 17.7 \\
\hline TSHMU/L & $0.65-3.70$ & $<0.015$ & 1.76 & $<0.015$ & $<0.015$ & $<0.015$ & 0.021 \\
\hline TRAbIU/L & $0.0-1.5$ & 27.0 & & $>40.0$ & & & \\
\hline TSI & $50-179 \%$ & & & & & & \\
\hline $\begin{array}{l}\text { Event and/or } \\
\text { Intervention }\end{array}$ & & $\begin{array}{c}\text { Diagnosed with } \\
\text { Graves' disease. } \\
\text { Started } \\
\text { Carbimazole } \\
30 \text { mg OM }\end{array}$ & $\begin{array}{c}\text { Carbimazole } \\
\text { stopped }\end{array}$ & $\begin{array}{l}\text { Graves } \\
\text { disease } \\
\text { relapsed }\end{array}$ & $\begin{array}{c}\text { Underwent total } \\
\text { thyroidectomy. } \\
\text { Started LT4 } 75 \mu \mathrm{g} \\
\text { OM }\end{array}$ & $\begin{array}{c}\text { LT4 reduced } \\
\text { to } 50 \mu g \\
\text { OM }\end{array}$ & $\begin{array}{c}\text { LT4 reduced } \\
\text { to } 25 \mu \mathrm{g} \\
\text { OM }\end{array}$ \\
\hline
\end{tabular}

27.0 IU/L (reference: 0.0-1.5 IU/L). She was diagnosed with Graves' disease and commenced on carbimazole. Anti-thyroid drug treatment was tapered and stopped in February 2015 after 18 months. However, the disease relapsed in June 2015 when she was hospitalized with high-output congestive cardiac failure (Table 1). She subsequently developed dysphagia and underwent a CT neck, which demonstrated mild narrowing of the trachea and indentation of the esophagus by the large multinodular goiter. She subsequently underwent total thyroidectomy on 9th March 2016. Histology revealed multinodular goiter with a background of lymphocytic thyroiditis. Postoperatively, she was immediately commenced on levothyroxine $75 \mu \mathrm{g} /$ day $(1.6 \mu \mathrm{g} / \mathrm{kg} /$ day $)$. However, she remained biochemically hyperthyroid; thus levothyroxine was tapered over the following eight months to $12.5 \mu \mathrm{g}$ five times a week, $25 \mu \mathrm{g}$ two times a week $(0.3 \mu \mathrm{g} / \mathrm{kg} /$ day $)$.

In August 2016, five months post thyroidectomy, our patient had a CT colonography to investigate per rectal bleeding, which revealed a large multiseptated cystic lesion with radiological characteristics of a mature cystic teratoma (Fig. 1). Her serum CA 125 was also raised at 75.1 (reference: $<35.1 \mathrm{U} / \mathrm{mL}$ ). She was referred to a gynecologist for surgical removal of the ovarian tumor.

In the same month, she was admitted with binocular diplopia of three-week duration. Physical examination and orbital MRI findings were consistent with features of moderate-to-severe active GO (Fig. 2). Initially, treatment with pulsed IV methylprednisolone was planned. However, this treatment was subsequently aborted due to a subsequent diagnosis of latent tuberculosis. She was treated with oral prednisolone $30 \mathrm{mg} /$ day, which was gradually tapered.

\section{Investigation}

Please refer to main text, Figs 1 and 2 and Table 1.
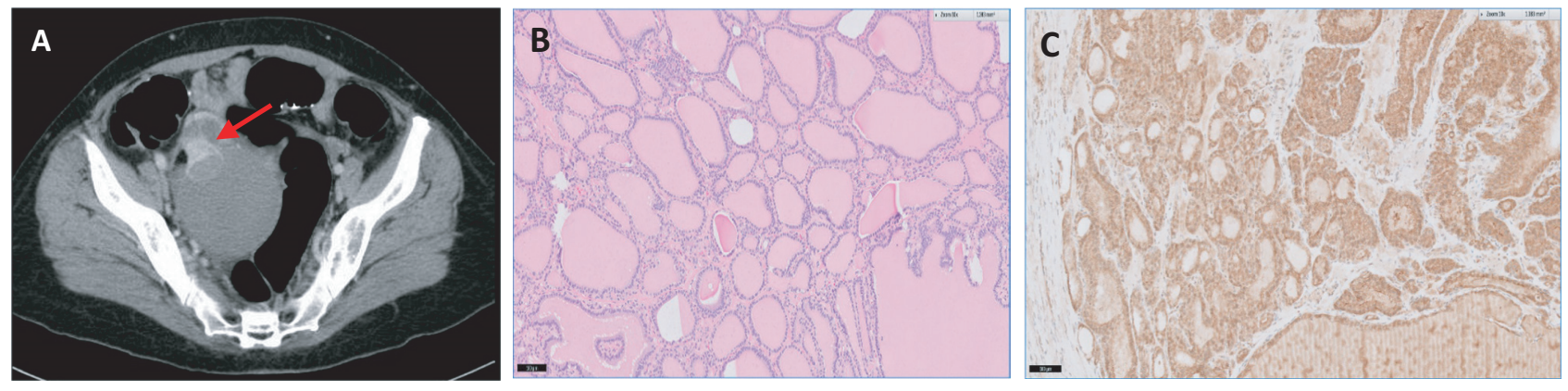

Figure 1

(A): A $8.1 \times 5.0 \mathrm{~cm}$ multiseptated cystic ovarian lesion on CT colonography. One of these locules measured $3.9 \times 2.9 \mathrm{~cm}$ and contained internal fat and calcification, compatible with mature cystic teratoma. (B) Struma ovarii component of the ovarian mass, which is composed of variably sized thyroid follicles containing colloid ( $\mathrm{H} \& \mathrm{E}, \times 100$ magnification); (C) Struma ovarii showing positivity for anti-thyroid-stimulating hormone receptor (1:2000 dilution; standard immunoperoxidase visualisation method; $\times 100$ magnification). 


\begin{tabular}{|c|c|c|}
\hline Aug 2016 & Sep 2016 & Nov 2016 \\
\hline & 6.0 & \\
\hline 10.8 & 13.2 & 15.2 \\
\hline 0.034 & 0.059 & 0.025 \\
\hline $\begin{array}{c}\text { CT colonography } \\
\text { showed } \\
\text { multiseptated } \\
\text { ovarian tumor } \\
\text { diagnosed with } \\
\text { thyroid eye disease }\end{array}$ & $\begin{array}{c}\text { LT4 reduced to } \\
25 \mu \mathrm{g} 4 \text { times } \\
\text { a week, } \\
12.5 \mu \mathrm{g} 3 \\
\text { times a week }\end{array}$ & $\begin{array}{c}\text { LT4 reduced to } \\
12.5 \mu \mathrm{g} 5 \text { times } \\
\text { a week, } 25 \mu \mathrm{g} \\
2 \text { times a week }\end{array}$ \\
\hline
\end{tabular}

\begin{tabular}{c}
\hline Dec 2016 \\
\hline 14.3 \\
$<0.015$ \\
\\
Underwent total \\
hysterectomy and \\
bilateral salpingo- \\
oopherectomy
\end{tabular}

\begin{tabular}{c}
\hline Dec 2016 \\
\hline 4.2 \\
7.0 \\
4.76 \\
\\
LT4 \\
increased \\
to $25 \mu \mathrm{g}$ \\
OM \\
\\
\end{tabular}

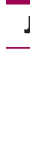

Jan 2017

Mar 2017

fT3, free T3; fT4, free T4; LT4, Levothyroxine; OM, every morning; TRAb, TSH receptor antibody; TSH, Thyroid-stimulating hormone; TSI, Thyroidstimulating immunoglobulins.

\section{Treatment}

She underwent total hysterectomy and bilateral salpingooophorectomy in December 2016 to remove a $12 \times 9 \times 9 \mathrm{~cm}$ right ovarian tumor. This was reported as a mature cystic teratoma with a large component of struma ovarii. There was no immature component, dysplasia or malignancy seen, and the peritoneal fluid was negative for malignant cells. The tumor cells stained positive for anti-TSH receptor (Fig. 1).

\section{Outcome and follow-up}

Postoperatively, she became hypothyroid and her levothyroxine dosage was up-titrated to full replacement dose based on her body weight at $75 \mu \mathrm{g} /$ day (Table 1), with achievement of complete euthyroidism by four months after surgery. Her TRAb and thyroid-stimulating immunoglobulin (TSI) levels declined after resection of the ovarian teratoma. She continues to have active thyroid eye disease with restrictive myopathy six months after resection of the struma ovarii and remains on oral prednisolone at a dose of $10 \mathrm{mg} /$ day.

\section{Discussion}

Struma ovarii represents $0.5-1.0 \%$ of ovarian tumors (1) and about $3.0 \%$ of all ovarian teratomas. It is defined as an ovarian teratoma, which contains more than $50 \%$ of thyroid tissue. It rarely produces adequate thyroid hormone to cause hyperthyroidism - thyrotoxicosis has been reported in $5-15 \%$ of cases and is more common in tumors more than $3 \mathrm{~cm}$ in size (2). The expression of TSH receptor in ovarian tissue in the presence of $\mathrm{TRAb}$ is indicative of a functioning struma ovarii as was demonstrated in our patient (3).

Struma ovarii accompanying Graves' disease is uncommon, with 16 cases reported in the literature to date (4). It commonly occurs in the fourth to sixth decade of life, is usually benign and unilateral. The diagnosis of struma ovarii often lags behind that of Graves' disease by up to more than 20 years (4). The
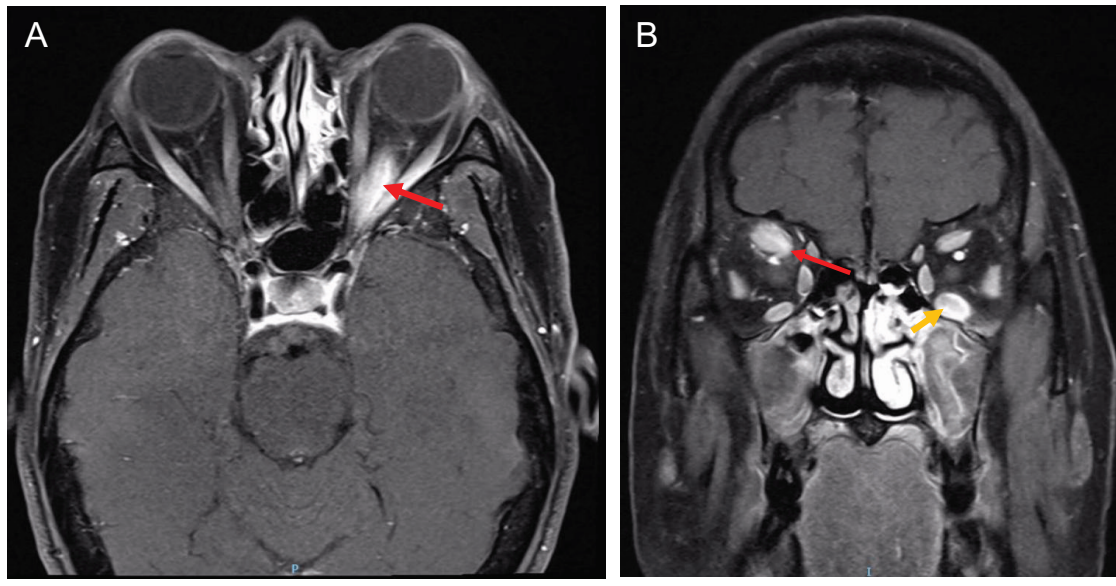

Figure 2

(A) MRI orbits (T1, sagittal view) demonstrating bilateral proptosis, thickening and enhancement of the muscle belly of the left inferior rectus muscle (red arrow). Mild crowding is seen at both orbital apices. (B) MRI orbits (T1, coronal view) demonstrating thickening and enhancement of the muscle belly of the right superior rectus (red arrow) and left inferior rectus (yellow arrow). 
underlying pathophysiology is stimulation of thyroid tissue present in the ovary by circulating TRAb in Graves' disease, which results in gradual growth and thyroid hormone synthesis from the struma ovarii. The increased thyroid hormone synthesis in such patients can be a result of production of thyroid hormone from the struma ovarii alone, both the hyperfunctioning thyroid gland as well as the struma ovarii or a hyperfunctioning thyroid gland with a concurrent non-functioning struma ovarii (4). Our patient presented with persistent hyperthyroidism after total thyroidectomy. On hindsight, a technetiumpertechnetate-99m (Tc ${ }^{99 m}$ ) or iodine-123 radioisotope (I123) whole-body scan could have been helpful in identifying ectopic hyperfunctioning thyroid tissue in the ovary indicative of a functioning struma ovarii.

$\mathrm{GO}$ is the most common extra-thyroidal manifestation of Graves' disease. The underlying pathophysiology of GO is still not fully understood. It is postulated that the TSH receptor (TSHR) serves as an autoantigen common to both thyroid and orbital tissue. Autoimmunity directed against TSHR on the orbital cells sets in motion connective tissue remodeling within the orbit that leads to the various clinical expressions of GO. Accumulation of glycosaminoglycans, expansion of orbital adipose tissue and local inflammation are features of the disease. Orbital fibroblasts express functional TSHR and are considered to be the target cells (5). While the development of GO after radioactive iodine has been well documented, total thyroidectomy for the treatment of hyperthyroidism has been shown to lower the risk of developing GO or even result in its regression due to (1) removal of shared antigen and intrathyroidal autoreactive T lymphocytes and (2) reduction in TRAB levels (6). The lack of GO improvement following thyroidectomy in reported cases could be caused by the persistence of even minimal residual thyroid tissue, which could have a role in maintaining orbital autoimmune phenomenon (6). In addition, TRAB may take several years to normalize even after total thyroidectomy (7). Hence, it is likely that the presence of the autoantigen TSH receptor on the struma ovarii perpetuated thyroid hormone production and persistence of TRAB, contributing to the development of GO in our patient. Although the early occurrence of hypothyroidism after treatment of hyperthyroidism has been shown to confer an increased risk for the development or deterioration of GO (8), our patient was given levothyroxine immediately after total thyroidectomy, minimizing this likelihood.
Thyroid-stimulating immunoglobulins (TSI) were markedly elevated in our patient. Interestingly, TSI has been shown to correlate better with ophthalmopathy in oriental patients with Graves' disease (9). These antibodies are proposed to stimulate orbital TSH receptors and mediate GO and are more prevalent in moderateto-severe GO (10). Antibody titres are also significantly higher in severe active GO compared with milder active GO. The significant elevation and continued presence of TSI in our patient even after oophorectomy could explain the persistence of active thyroid eye disease.

In summary, we described a case of concomitant Graves' disease and struma ovarii in a patient who remained hyperthyroid and developed de novo moderate-to-severe active GO after total thyroidectomy. It is important to consider ectopic thyroid hormone production in a patient with Graves' disease who remains persistently hyperthyroid after total thyroidectomy. De novo GO is rare after complete thyroid gland resection. In our case, this was attributed to the presence of struma ovarii.

\section{Declaration of interest}

The authors do not have any conflict of interest that could be perceived as prejudicing the impartiality of the research reported.

\section{Funding}

This research did not receive any specific grant from any funding agency in the public, commercial or not-for-profit sector.

\section{Patient consent}

The patient has provided consent for publication of this case report (signed consent attached).

\section{Author contribution statement}

All 4 authors contributed to the writing of this case report. Additional duties are as follows: W L Tay: primary author of this case report, physician currently participating in the care of the featured patient. W J Loh: Physician who first participated in the care of the featured patient. $L A L$ Lee: Pathologist who provided the histology slides. C L Chng: Mentor and guidance for this case report.

\section{References}

1 Yoo S-C, Chang K-H, Lyu M-O, Chang S-J, Ryu H-S \& Kim H-S 2008 Clinical characteristics of struma ovarii. Journal of Gynecologic Oncology 19 135-138. (doi:10.3802/jgo.2008.19.2.135)

2 Kempers RD, Dockerty MB, Hoffman DL \& Bartholomew LG 1970 Struma ovarii - ascitic, hyperthyroid, and asymptomatic syndromes. Annals of Internal Medicine 72 883-893. (doi:10.7326/0003-4819 $-72-6-883)$ 
3 Teale E, Gouldesbrough DR \& Peacey SR 2006 Graves' disease and coexisting struma ovarii: struma expression of thyrotropin receptors and the presence of thyrotropin receptor stimulating antibodies. Thyroid 16 791-793. (doi:10.1089/thy.2006.16.791)

4 Anastasilakis AD, Ruggeri RM, Polyzos SA, Makras P, Molyva D, Campennì A, Gkiomisi A, Balaris C, Fotiadis PP, Tuccari G, et al. 2013 Coexistence of Graves' disease, papillary thyroid carcinoma and unilateral benign struma ovarii: case report and review of the literature. Metabolism 62 1350-1356. (doi:10.1016/j.metabol.2013.05.013)

5 Iyer S \& Bahn R 2012 Immunopathogenesis of Graves' ophthalmopathy: the role of the TSH receptor. Best Practice and Research Clinical Endocrinology and Metabolism 26 281-289. (doi:10.1016/j.beem.2011.10.003)

6 De Bellis A, Conzo G, Cennamo G, Pane E, Bellastella G, Colella C, Iacovo AD, Paglionico VA, Sinisi AA, Wall JR, et al. 2012 Time course of Graves' ophthalmopathy after total thyroidectomy alone or followed by radioiodine therapy: a 2-year longitudinal study. Endocrine 41 320-326. (doi:10.1007/s12020-011-9559-x)
7 Takamura Y, Nakano K, Uruno T, Ito Y, Miya A, Kobayashi K, Yokozawa T, Matsuzuka F, Kuma K \& Miyauchi A 2003 Changes in serum TSH receptor antibody (TRAb) values in patients with Graves' disease after total or subtotal thyroidectomy. Endocrine Journal 50 595-601. (doi:10.1507/endocrj.50.595)

8 Wiersinga WM \& Bartalena L 2002 Epidemiology and prevention of Graves' ophthalmopathy. Thyroid 12 855-860. (doi:10.1089/1050725 02761016476)

9 Khoo DH, Ho SC, Seah LL, Fong KS, Tai ES, Chee SP, Eng PH, Aw SE \& Fok AC 1999 The combination of absent thyroid peroxidase antibodies and high thyroid-stimulating immunoglobulin levels in Graves' disease identifies a group at markedly increased risk of ophthalmopathy. Thyroid 9 1175-1180. (doi:10.1089/ thy.1999.9.1175)

10 Chng C-L, Seah LL \& Khoo DHC 2012 Ethnic differences in the clinical presentation of Graves' ophthalmopathy. Best Practice and Research Clinical Endocrinology and Metabolism 26 249-258. (doi:10.1016/j.beem.2011.10.004)

Received in final form 11 August 2017

Accepted 25 September 2017 